\title{
Identification of Motifs Involved in Endoplasmic Reticulum Retention-Forward Trafficking of the GLT-1 Subtype of Glutamate Transporter
}

\author{
Avtandil Kalandadze, Ying Wu, Keith Fournier, and Michael B. Robinson \\ Departments of Pediatrics and Pharmacology, Children's Hospital of Philadelphia, University of Pennsylvania, Philadelphia, Pennsylvania 19104
}

\begin{abstract}
Glutamate transporters may exist as homomultimers, but little is known about the mechanisms that ensure proper assembly and surface expression. In the present study, we investigated the mechanisms that contribute to posttranslational processing of the GLT-1 subtype of glutamate transporter. An extracellular leucine-based motif was identified that after mutation to alanine (6L/6A GLT-1) prevented export of GLT-1 from the endoplasmic reticulum (ER) to the plasma membrane and displayed a glycosylation pattern characteristic of "immature" transporter. This 6L/6A variant had a selective dominant-negative effect on wild-type GLT-1 expression and formed coimmunoprecipitable complexes with GLT-1. Mutation of two downstream arginine residues to alanine partially restored maturation and functional activity of the $6 \mathrm{~L} / 6 \mathrm{~A}$ variant. The fact that this additional mutation rescued maturation of GLT- 1 essentially excludes the possibility that the $6 \mathrm{~L} / 6 \mathrm{~A}$ mutant variant is not appropriately processed because of simple misfolding. When the domain containing these motifs was introduced into a topologically similar location in the interleukin $2 \alpha$ receptor subunit (Tac protein), the mutations had a similar effect on protein maturation. Topological models place at least the leucine-based motif in an extracellular domain, which would face the lumen of the ER during assembly. On the basis of these data, we suggest that an evolutionarily conserved arginine-based motif functions as an ER retention signal and a lumenal leucine motif is required for suppression of this signal. Interestingly, a high percentage of variably spliced GLT-1 mRNAs lacking parts of this domain are found in the CNS, suggesting that GLT-1 expression may be regulated during assembly.
\end{abstract}

Key words: glutamate transporter; GLT-1; assembly; trafficking; ER retention; uptake

\section{Introduction}

Five subtypes of sodium-dependent glutamate transporters have been identified with different regional and cellular expression patterns (Amara et al., 1998; Sims and Robinson, 1999; Danbolt, 2001). The glial transporter, GLT-1 [excitatory amino acid transporter 2 (EAAT2)], may represent the predominant route for clearance of extracellular glutamate in forebrain (Haugeto et al., 1996; Rothstein et al., 1996; Tanaka et al., 1997; for review, see Robinson, 1999). At some synapses, binding of synaptically released glutamate to GLT-1 "buffers" the amount of glutamate available for receptor activation on a rapid time scale (Tong and Jahr, 1994). At others, the uptake via GLT-1, which is slower than binding, can shape the time course for receptor activation by controlling synaptic glutamate clearance (Mennerick et al., 1999). Genetic deletion or antisense knockdown of GLT-1 results

\footnotetext{
Received March 8, 2004; revised April 20, 2004; accepted April 25, 2004

This work was supported by National Institutes of Health Grants NS36465 and NS39011 to M.B.R. In addition, the cores that provided support (cellular neuroscience and molecular genetics) for this work were supported by the Mental Retardation Developmental Disabilities Research Center (P30 HD26979). We thank Dr. Olga Zelenaia for her helpful ideas during the development of this project, Dr. Jeffrey Rothstein for his generous contribution of antitransporter antibodies, Dr. Juan Bonifacino for the human IL-2 CDNA, Dr. Baruch Kanner for the GLT-1 CDNA, Dr. Mathias Hediger for the EAAC1 CDNA, and Amanda Sheldon, Dr. González, and Dr. Susarla for their helpful comments regarding the preparation of this manuscript.

Correspondence should be addressed to Michael B. Robinson, 502 N. Abramson Pediatric Research Building, 3615 Civic Center Boulevard, Philadelphia, PA 19104-4318. E-mail: robinson@pharm.med.upenn.edu.

D0I:10.1523/JNEUROSCI.0839-04.2004

Copyright $\odot 2004$ Society for Neuroscience $\quad$ 0270-6474/04/245183-10\$15.00/0
}

in excitotoxicity (Rothstein et al., 1996; Tanaka et al., 1997). Collectively, these results are consistent with the conclusion that GLT-1 is critical for the maintenance of normal glutamate homeostasis.

The endoplasmic reticulum (ER) is the site of synthesis, maturation, and assembly of proteins destined for the plasma membrane as well as for secretory and endocytic organelles (Teasdale and Jackson, 1996; Ellgaard and Helenius, 2003). In the case of multimeric complexes, retention ensures that only properly assembled multimers are exported from the ER to the Golgi. Misfolded or incorrectly assembled proteins are retained in the ER and frequently targeted for degradation, providing quality control during protein assembly (Hurtley and Helenius, 1989; Klausner and Sitia, 1990). At least two types of mechanisms contribute to this quality control. The first provides a general surveillance system that screens for broad conformational characteristics such as appropriate membrane partitioning of hydrophobic domains or unpaired cysteine residues. The second is more selective for particular classes of proteins. This system is thought to depend on presentation of specific motifs interacting with chaperone proteins that escort complexes through the ER or Golgi, but only a limited number of these motifs have been identified (Ellgaard and Helenius, 2003).

Glutamate transporters are thought to exist as noncovalently connected homomultimers (Haugeto et al., 1996). A recent freeze-fracture electron microscopy study suggests that these 
transporters may be pentamers (Eskandari et al., 2000). Although progress has been made in understanding the functional regulation of GLT-1 (Sims and Robinson, 1999; Danbolt, 2001; González and Robinson, 2004), mechanisms governing assembly and progression of transporter complexes through the secretory pathway have not been identified.

We identify leucine- and arginine-based motifs that are necessary for exit of GLT-1 complexes from the ER and their forward trafficking through the secretory pathway. Mutation of the leucine motif results in retention of the resulting protein in the ER. In addition, transporters lacking this motif have a dominantnegative effect on wild-type GLT-1. This ER retention can be reversed by combining mutations of both the leucine and arginine motifs; the resulting double mutant exits the ER and traffics to the cell surface. These data suggest that the arginine motif is masked in assembled GLT-1 complexes and that the leucinebased motif is required for suppression of this retention signal.

\section{Materials and Methods}

Cell culture. C6 glioma, COS7, or human embryonic kidney (HEK) 293 cells were maintained in DMEM, supplemented with 10\% FBS, 2 mM glutamine, $100 \mathrm{U} / \mathrm{ml}$ penicillin, $100 \mu \mathrm{g} / \mathrm{ml}$ streptomycin and incubated at $37^{\circ} \mathrm{C}$ in $5 \% \mathrm{CO}_{2}$. Tissue culture media and chemicals were obtained from Invitrogen (Gaithersburg, MD). C6 glioma, COS7, and HEK293 cells were acquired from American Type Tissue Collection (Rockville, MD).

cDNA constructs. GLT-1 and EAAC1 cDNAs were subcloned into the expression vector pcDNA 3.1 (Invitrogen, Carlsbad, CA). All mutants were made using PCR and $5^{\prime}$-mutagenic primers at unique BstE II or PshA1 restriction sites to amplify 385 or 339 base pair fragments of GLT-1 between $B s t$ E II-XbaI and PshA1-XbaI restriction sites, respectively. Amplified fragments were subcloned back into the expression vector pcDNA-GLT-1. Hemagglutinin (HA), YPYDVPDYA, or FLAG, DYKDDDDK, epitopes were introduced at the $\mathrm{N}$ termini after the start Met codon by PCR. The interleukin IL $\alpha$ (Tac) constructs were generated by overlapping PCR amplification. The sequences of all constructs were verified by sequencing at the molecular biology core at the Children's Hospital of Philadelphia.

Transfection. C6 glioma, COS7, or HEK 293T cells were grown to between 60 and $70 \%$ confluence in $10 \mathrm{~cm}$ dishes before transfection with wild-type or mutant cDNA expression plasmids using the cationic lipidbased procedure, GenePorter (Gene Therapy Systems, San Diego, CA). Cells plated in $10 \mathrm{~cm}$ dishes were transfected with $10-16 \mu \mathrm{g}$ of DNA mixed with $60 \mu \mathrm{l}$ of GenePorter reagent. The amounts of DNA-GenePorter were adjusted for surface area per number of cells in 12-well plates. After incubation for 3-5 hr in $5 \mathrm{ml}$ DMEM, an additional $5 \mathrm{ml}$ of modified medium (DMEM containing 20\% FBS, 4 mM glutamine, and 200 $\mathrm{U} / \mathrm{ml}$ penicillin, $200 \mu \mathrm{g} / \mathrm{ml}$ streptomycin) was added, and cells were maintained for an additional $15 \mathrm{hr}$. In initial experiments, we found that protein maturation was somewhat slower in COS7 cells; therefore, these cells were maintained for $48 \mathrm{hr}$ after introduction of the cDNAs.

Labeling of cell-surface proteins. Cells were rinsed with ice-cold PBS containing $0.1 \mathrm{mM} \mathrm{CaCl}_{2}$ and $1.0 \mathrm{mM} \mathrm{MgCl}_{2}$ and were incubated in the same solution supplemented with $1 \mathrm{mg} / \mathrm{ml} \mathrm{N}$-hydroxysulfosuccinimidobiotin (Pierce, Rockford, IL) for $20 \mathrm{~min}$ at $4^{\circ} \mathrm{C}$. After incubation, cells were rinsed several times with $\mathrm{PBS}-\mathrm{Ca} / \mathrm{Mg}$ containing $100 \mathrm{~mm}$ glycine and incubated in this buffer for $30 \mathrm{~min}$ at $4^{\circ} \mathrm{C}$ to quench the unreacted biotin. Cells were lysed with radioimmunoprecipitation assay (RIPA) lysis buffer with protease inhibitors. Biotinylated proteins were batch extracted using avidin-coated beads.

Measurement of $\mathrm{Na}^{+}$-dependent transport activity. $\mathrm{Na}^{+}$-dependent $\mathrm{L}-\left({ }^{3} \mathrm{H}\right)$-glutamate $(44 \mathrm{Ci} / \mathrm{mmol})$ or $\mathrm{L}-\left({ }^{35} \mathrm{~S}\right)$-cysteine $(1075 \mathrm{Ci} / \mathrm{mmol})$ (PerkinElmer Life Sciences, Boston, MA) uptake was measured as described previously (Davis et al., 1998). Briefly, cells were grown in a monolayer on 12-well plates and then rinsed twice with $1 \mathrm{ml}$ of warmed $\left(37^{\circ} \mathrm{C}\right)$ sodium- or choline-containing buffer before incubation with radioisotope $(0.5 \mu \mathrm{Ci} \mathrm{L-glutamate}$ and $0.5 \mu \mathrm{Ci} \mathrm{L-cysteine})$ in sodium- or choline-containing buffer for $5 \mathrm{~min}$. After stopping uptake with ice-cold choline-containing buffer, cells were solubilized in $0.1 \mathrm{~N} \mathrm{NaOH}$. Aliquots of the cell lysate were analyzed for protein and radioactivity. $\mathrm{Na}^{+}$dependent uptake was defined as the difference between the signal observed in the sodium- and choline-containing buffer.

Immunoprecipitation. For immunoprecipitation of transporters, the supernatant of cell lysate (lysis buffer: $50 \mathrm{~mm}$ Tris, $1 \mathrm{~mm}$ EDTA, $100 \mathrm{~mm}$ $\mathrm{NaCl}, 1 \%$ Triton $\mathrm{X}-100$, and $0.1 \%$ SDS for $\mathrm{HA}$ or $1 \% 3-[(3-$ cholamidopropyl)dimethylammonio]-1-propanesulfonate for FLAG, $\mathrm{pH}$ 8.0) was first precleared by incubation for $1 \mathrm{hr}$ at $4^{\circ} \mathrm{C}$ with agaroseconjugated rabbit serum (Sigma, St. Louis, MO). After centrifugation, the cleared lysate was incubated overnight at $4^{\circ} \mathrm{C}$ with anti-HA (Boehringer Mannheim, Indianapolis, IN) $(5 \mu \mathrm{g})$ or anti-FLAG $(5 \mu \mathrm{g})$ antibody (Sigma). Antibody-antigen complexes were precipitated by incubation with prewashed protein $\mathrm{G}$ agarose (Invitrogen) for $2 \mathrm{hr}$ at $4^{\circ} \mathrm{C}$. The protein $\mathrm{G}$ agarose beads were washed four times in lysis buffer and resuspended in $50 \mu \mathrm{l}$ sample buffer (50 mm Tris-HCl, pH 6.8, 2\% SDS, $0.1 \%$ bromophenol blue, $10 \%$ glycerol, $100 \mathrm{~mm}$ dithiothreitol).

Deglycosylation. C6 glioma cells plated on $10 \mathrm{~cm}$ dishes were transfected with plasmid DNA as described above. Cells were harvested $24 \mathrm{hr}$ later in RIPA lysis buffer. Samples were denatured in buffer containing $0.5 \%$ SDS and $1 \% \beta$-mercaptoethanol at $100^{\circ} \mathrm{C}$ for $10 \mathrm{~min}$ and treated according to the manufacturer's instructions (Boehringer Mannheim) with $2500 \mathrm{U}$ of endoglycosidase $\mathrm{H}$ (Endo $\mathrm{H}$ ) in $50 \mathrm{~mm}$ sodium citrate buffer, $\mathrm{pH} 5.5$, or $2500 \mathrm{U}$ of $\mathrm{N}$-glycosidase F (PNGase F) in $50 \mathrm{~mm}$ sodium phosphate buffer, $\mathrm{pH} 7.5$, with $1 \% \mathrm{NP}-40$ at $37^{\circ} \mathrm{C}$ for $1 \mathrm{hr}$. Reactions were terminated by adding SDS-PAGE sample buffer.

SDS-PAGE and immunoblot analysis. Proteins were separated with SDS-PAGE (10\% gels). The contents of the complete resolving gel were transferred to polyvinylidene difluoride (Millipore, Bedford MA) membranes. After blocking in Tris-buffered saline (TBS)-T (50 mM Tris, $\mathrm{pH}$ 8.0, $150 \mathrm{~mm} \mathrm{NaCl}, 0.2 \%$ Tween) containing $5 \%$ nonfat dry milk, membranes were incubated with anti-GLT-1 $(1: 10,000)$, anti-excitatory amino acid carrier (EAAC1) (1:75), anti-glutamate-aspartate transporter (GLAST) (1:75), anti-actin (1:4000), anti-HA (1:500), anti-FLAG (1:1000), or anti-Tac (1:600) antibodies. After removal of the primary antibodies, membranes were washed and then incubated with horseradish peroxidase-linked donkey anti-rabbit (1:5000) or anti-mouse $(1: 10,000)$ IgGs, and proteins were visualized by enhanced chemiluminescence. Polyclonal anti-GLT-1, anti-EAAC1, and anti-GLAST antibodies were gifts from Dr. Rothstein (Johns Hopkins, Baltimore, MD) (Rothstein et al., 1995). The anti-Tac antibody was from Santa Cruz Biotechnology (Santa Cruz, CA). Essentially every experiment included lysate from nontransfected cells. As reported previously (Kalandadze et al., 2002), no cross-reacting bands were observed in untransfected cells (these data were not shown, except in Fig. 7A). In some cases, darker exposures of the films were presented so that expression of all of the transporters could be observed. When appropriate, lighter exposures of the films were quantified to ensure that the films were not saturated. Except for Figure 9, the Western blots include from the bottom of the stacking gel to below $\sim 40 \mathrm{kDa}$ where they were cropped using Photoshop to eliminate this blank portion of the immunoblot.

Immunocytochemistry and confocal microscopy. C6 glioma cells were plated on glass coverslips in sterile $35 \mathrm{~mm}$ dishes. After cooling to $4^{\circ} \mathrm{C}$, the coverslips were removed and washed twice with PBS before being fixed with $4 \%$ paraformaldehyde for $10 \mathrm{~min}$. After coverslips were rinsed in TBS, they were placed in blocking solution (5\% goat serum and $0.1 \%$ Triton X-100 in TBS) for $30 \mathrm{~min}$ and then subsequently incubated overnight at $4^{\circ} \mathrm{C}$ with mouse anti-FLAG $(20 \mu \mathrm{g} / \mathrm{ml}$; Sigma $)$ and rabbit antiGRP78 ( $1 \mu \mathrm{g} / \mathrm{ml}$; Affinity Bioreagents, Golden, CO). After three washes with blocking solution, coverslips were incubated with 1:100 dilutions of anti-mouse fluorescine and anti-rabbit rhodamine (Jackson ImmunoResearch, West Grove, PA) for $30 \mathrm{~min}$ at room temperature. After Hoechst staining and mounting with Vectashield (Vector Laboratories, Burlingame, CA) medium on glass microscope slides, immunolabeled cultures were optically sectioned at $0.5 \mu \mathrm{m}$ intervals with a Leica (Nussloch, Germany) Inverted DM IRE2 HC fluo TCS 1-B-UV microscope coupled to a Leica TCS SP2 spectral confocal system/UV. We confirmed that in the absence of primary antibodies no signal was observed and that 


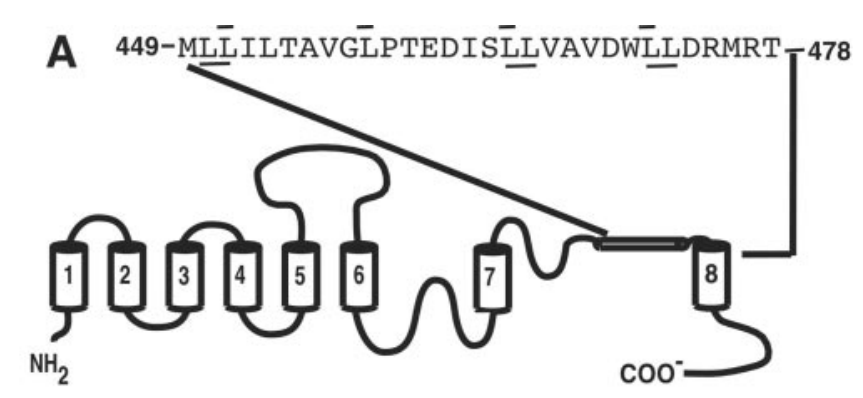
B 6L/6A-MLAIATAVGAPTEDISAAVAVDWALDRMRT 4L4A - MLA ILTAVGAPTEDISALVAVDWALDRMRT 2L/2A-1 - MAAILTAVGLPTEDISLLVAVDWLLDRMRT 2L/2A-2-MLLILTAVGLPTEDISAAVAVDWLLDRMRT 6L/6A-2R/2A-MLAI ATAVGAPTEDISAAVAVDWALDAMAT 2R/2A-MLLILTAVGLPTEDISLLVAVDWLLDAMAT 3P-MLLILTPVGLPTEPISLLVAVPWLLDRMRT

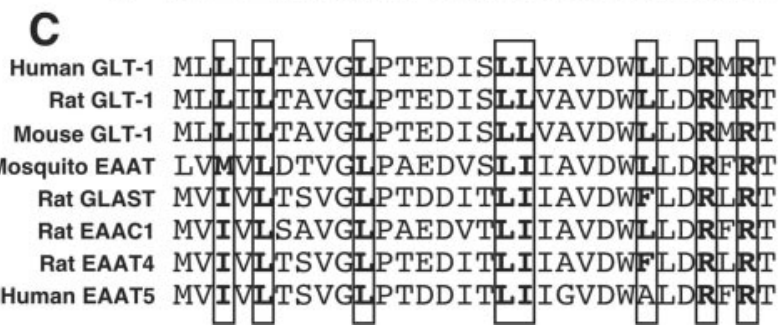

Figure 1. Structure of wild-type and mutant variants of GLT-1. A, Schematic topological model of GLT-1 based on that proposed by Grunewald and Kanner (2000). Location and sequence of C-terminal domain that contains a heptad leucine repeat characteristic of a leucine zipper (overscore line) and three dileucine motifs (underlined) is expanded. $B$, Mutant variants of the transporter generated for this study. Positions of mutations are depicted in bold and underlined. C, Sequence alignment of the domain thought to be required for posttranslational processing. This analysis includes the other members of the $\mathrm{Na}^{+}$-dependent glutamate transporter family and transporters from different species. The high degree of homology between transporters suggests that they use similar mechanisms to ensure appropriate posttranslational maturation.

the two secondary antibodies did not cross-react with antibodies from the other species.

\section{Results}

Identification of trafficking signals in a C-terminal domain

Our recent study suggested that a C-terminal domain might be involved in maturation and subsequent cell surface expression of glutamate transporters (Kalandadze et al., 2002). We hypothesized that this domain may contain signals required for posttranslational processing. In this domain of GLT-1, we identified a heptad leucine repeat characteristic of leucine zippers (leucines $451,458,465$, and 472); three of these leucine residues are part of dileucine motifs (Fig. 1A). To study the involvement of the leucine residues in GLT-1 assembly and sorting, a family of GLT-1 variants was created with different combinations of these leucine residues mutated to alanine (Fig. $1 B$ ). Wild-type or mutant variants of GLT-1 were transiently transfected into C6 glioma. The degree of protein maturation and cell surface expression were determined by batch extraction of biotinylated proteins. In agreement with previously published results (Haugeto et al., 1996; Danbolt, 2001), wild-type GLT-1 protein migrates as a monomeric band, but also has a tendency to form multimers on SDS-PAGE (Fig. 2A). The molecular weight of the predominant multimer is consistent with a trimer. In addition, there is a larger molecular band that may represent a tetramer, but with these percentages of gels, the molecular weight cannot be determined accurately. The major monomer migrated as a broad band centering at $\sim 75 \mathrm{kDa}$, but a minor, faster migrating band of $\sim 60 \mathrm{kDa}$ was also observed; corresponding multimers of the smaller band were also observed. It has been suggested that the 75 and $60 \mathrm{kDa}$ bands represent "mature" (terminally glycosylated) and "immature" (partially glycosylated) forms of the protein (Grunewald et al., 1998), and they will be referred to in this manner because of data provided below.

Approximately $80 \%$ of the wild-type GLT- 1 migrated as the monomer and multimer of mature protein (Fig. $2 \mathrm{~B}$ ), and of that mature protein, $75 \%$ was expressed at the plasma membrane (Fig. 2C). Mutation of six leucine residues in an extracellular domain of GLT-1 to alanine $(6 \mathrm{~L} / 6 \mathrm{~A})$ completely eliminated the $75 \mathrm{kDa}$ band with its corresponding multimers (Fig. $2 A, B$ ) and abolished cell surface expression of the transporter. To determine whether the heptad repeat or the dileucine motifs, or both, are required for "maturation" and cell surface expression, these motifs were mutated separately to alanine residues. Although mutation of all four heptad leucines (4L/4A) reduced expression somewhat compared with control, most of the protein migrated as a mature form (not significantly different from GLT-1). Mutation of one of the dileucine motifs (2L/2A-1) had no effect on expression or maturation; however, mutation of the second dileucine motif (2L/2A-2) reproducibly decreased overall expression and maturation but to a lesser extent than that observed in $6 \mathrm{~L} / 6 \mathrm{~A}$.

The function of each of these transporter variants was also examined by measuring $\mathrm{Na}^{+}$-dependent glutamate transport activity. Expression of wild-type GLT-1 increased the level of transport above that observed in control cells to $\sim 180 \%$ of control (Fig. 2D). Consistent with the biotinylation studies, the $6 \mathrm{~L} / 6 \mathrm{~A}$ mutant variant did not increase transport activity at all. The levels of activity of the other variants roughly correlated with the percentage of protein that was mature (Fig. $2 B$ ) multiplied by the percentage of the mature protein that was expressed on the cell surface (Fig. 2C). On the basis of these data, we concluded that six leucine residues in this domain were the minimal determinants required for interruption of normal posttranslational processing of GLT-1 and that the resulting immature protein was retained intracellularly.

\section{Forward trafficking of mature GLT-1 is facilitated by a dileucine motif}

Examination of the cell surface expression of these mutant variants suggested that components of the six-leucine motif are required for forward trafficking of mature protein. Although elimination of subcomponents of this motif did not completely block maturation, two different mutants were not trafficked to the plasma membrane as efficiently as wild-type GLT-1 (Fig. 2C). Mutation of either the heptad repeat $(4 \mathrm{~L} / 4 \mathrm{~A})$ or one of the dileucine motifs (2L/2A-2) substantially reduced the percentage of mature protein that is trafficked to the cell surface, providing evidence that these residues are important for forward trafficking of mature protein to the plasma membrane. Because $4 \mathrm{~L} / 4 \mathrm{~A}$ and $2 \mathrm{~L} / 2 \mathrm{~A}-2$ share a mutation at position 465 , the simplest explanation is that this dileucine motif is required for cell surface expression (forward trafficking) of mature transporter.

\section{The diarginine motif may function as an ER retention signal} Additional analysis of this leucine-rich domain revealed a diarginine motif that is highly conserved in different glutamate transporters and immediately downstream of the leucine-rich domain (Fig. 1C). We hypothesized that this motif could function to prevent surface expression of the $6 \mathrm{~L} / 6 \mathrm{~A}$ mutant variant as part of 
a quality control mechanism. Mutation of the two arginine residues to alanine (2R/ 2A) in wild-type GLT-1 slightly reduces overall expression, but essentially all of the protein is mature and the level of cell surface expression is indistinguishable from wild-type GLT-1 (Fig. 3). Importantly, introduction of this mutation into the $6 \mathrm{~L} / 6 \mathrm{~A}$ mutant transporter $(6 \mathrm{~L} / 6 \mathrm{~A}-2 \mathrm{R} / 2 \mathrm{~A})$ partially restored maturation and cell surface expression of this protein. In fact, the percentage of mature $6 \mathrm{~L} / 6 \mathrm{~A}-2 \mathrm{R} / 2 \mathrm{~A}$ observed on the cell surface is as high as could be expected, because the dileucine motif that appears to be required for forward trafficking of mature protein (2L/2A-2) is absent in this construct (see previous paragraph). Therefore, although one might simply conclude that the $6 \mathrm{~L} / 6 \mathrm{~A}$ mutation causes misfolding, the fact that further mutation of the two downstream arginine residues rescues maturation and cell surface expression argues strongly that misfolding cannot explain the intracellular retention of the $6 \mathrm{~L} / 6 \mathrm{~A}$ variant. Instead, these data suggest that the argininebased motif functions as an ER retention signal and that the leucine motif is required for suppression of the retention signal.

\section{The leucine motif is required for ER escape and maturation of GLT-1}

On the basis of these observations, one would predict that the $6 \mathrm{~L} / 6 \mathrm{~A}$ variant of GLT-1 is retained in the ER. To test this prediction, C6 glioma cells were transfected with wild-type GLT-1 or $6 \mathrm{~L} / 6 \mathrm{~A}$ GLT-1 that were epitope tagged with FLAG. In optical cross sections of the cells, wild-type GLT-1 was essentially confined to the cell surface with almost no intracellular staining. In contrast, the $6 \mathrm{~L} / 6 \mathrm{~A} \mathrm{mu}$ tant variant was restricted to intracellular compartments (Fig. 4A), consistent with the lack of biotinylated surface protein (Fig. 2). Because our hypothesis was that the leucine motif suppresses an ER retention signal, we costained cells for the ER chaperone protein, $78 \mathrm{kDa}$ glucose regulated protein (GRP78). GRP78 (BiP) extensively colocalized with the $6 \mathrm{~L} / 6 \mathrm{~A}$ variant of GLT-1 and did not overlap with wild-type GLT-1 (Fig. 4A). These data indicate that the mutant variant of GLT-1 resides in the ER and are consistent with the hypothesis that this leucine motif functions to suppress an ER retention signal.

To determine whether the 60 and $75 \mathrm{kDa}$ bands and their corresponding multimers represent differentially glycosylated transporters, wild-type or the two mutant variants $(6 \mathrm{~L} / 6 \mathrm{~A}$ or $6 \mathrm{~L} / 6 \mathrm{~A}-2 \mathrm{R} /$ 2A) of GLT-1 were expressed in C6 glioma cells and treated with PNGase F or Endo H. PNGase F removes all Asn-linked glycans, whereas Endo $\mathrm{H}$ specifically recognizes only high-mannose-type carbohydrate backbones characteristic of partially glycosylated proteins resident in the proximal secretory pathway (ER to medialGolgi). After exit from the ER, proteins proceed through the secre- tory pathway, and most glycoproteins acquire Endo $\mathrm{H}$ resistance in the medial-Golgi (Huh and Wenthold, 1999). Therefore, insensitivity to Endo $\mathrm{H}$ can reflect the maturation state of glycoproteins. Consistent with a mature protein, wild-type GLT-1 was insensitive to Endo $\mathrm{H}$, but treatment with PNGase F decreased the molecular weight of the monomer band by $\sim 10-15 \mathrm{kDa}$ (Fig. $4 B$, bottom panel). In contrast, the $6 \mathrm{~L} / 6 \mathrm{~A}$ mutant variant of GLT-1 was sensitive to both Endo $\mathrm{H}$ and PNGase F, indicating that this protein is not terminally glycosylated and represents an immature form of the transporter. As might be expected, both monomer bands observed after expression of $6 \mathrm{~L} / 6 \mathrm{~A}-2 \mathrm{R} / 2 \mathrm{~A}$ are sensitive to PNGase F, but only the smaller $(\sim 60 \mathrm{kDa})$ band is sensitive to Endo $\mathrm{H}$, providing further evidence that the combination of the Arg and Leu mutations restores maturation of the transporter. The multimer bands displayed similar sensitivities to these endoglycosidases (Fig. $4 B$, top panel). These data provide complementary evidence that the leucine-based motif is required for maturation-ER to Golgi trafficking of GLT-1, unless the arginine-based motif is also eliminated by mutation. 
A
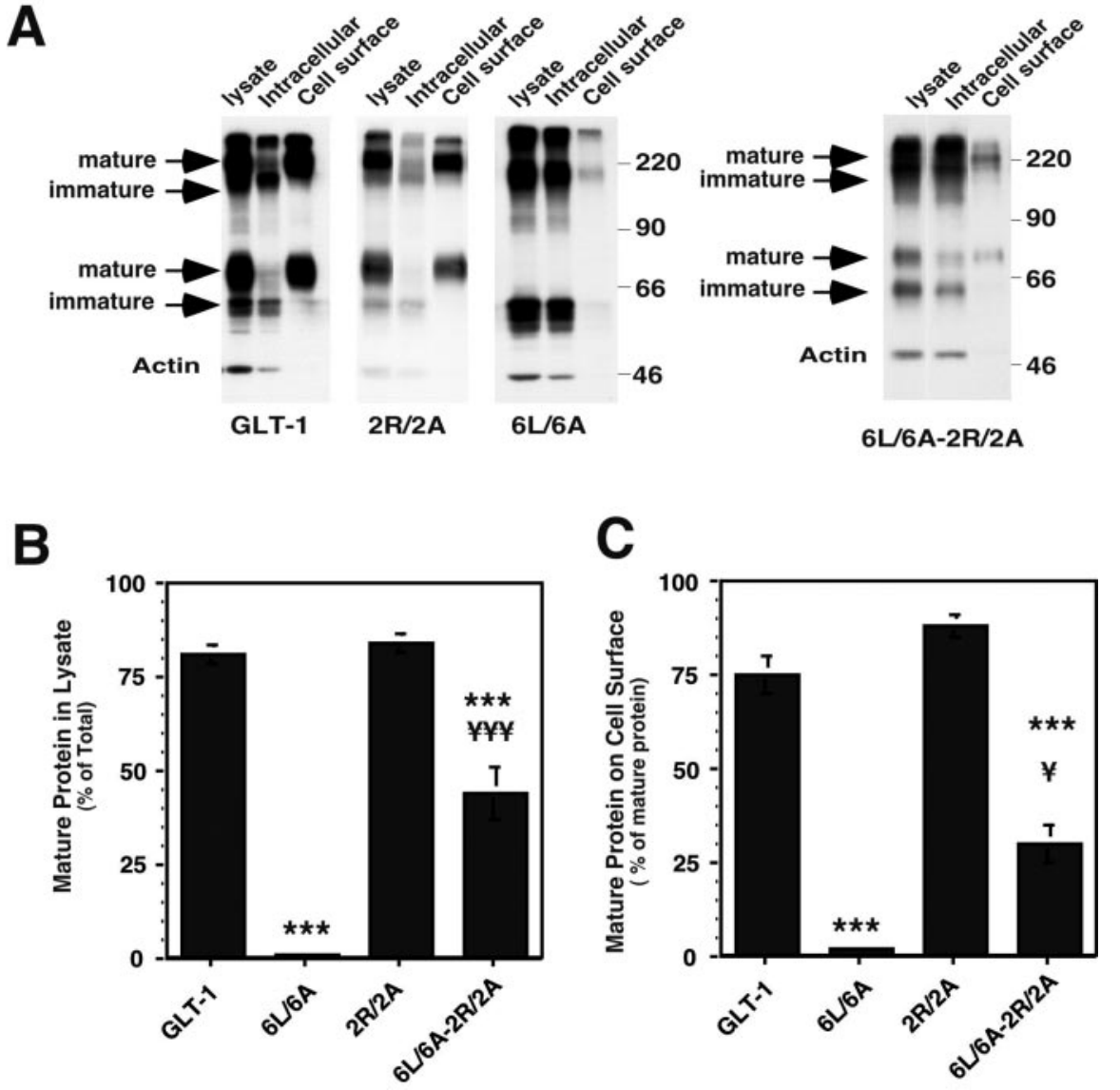

Figure 3. Mutation of two arginines downstream of the leucine motif partially restores maturation and cell surface expression of the $6 \mathrm{~L} / 6 \mathrm{~A}$ mutant variant of GLT-1. A, Expression pattern of wild-type and mutant variants of GLT-1. B, C, Quantification of maturation of wild-type and mutant variants of GLT-1 (Fig. 2 legend). Mutation of the two arginine residues in the $6 \mathrm{~L} / 6 \mathrm{~A}$ mutant variant partially restores maturation $(B)$ and cell surface expression ( $C$ ) of the transporter. Data are expressed as the mean \pm SEM of between three and seven independent observations and were compared by ANOVA. ${ }^{* *} p<0.001$ compared with GLT-1; ${ }^{*} p<$ 0.05 and ${ }^{\# \#} p<0.001$ compared with $6 \mathrm{~L} / 6 \mathrm{~A}$.

\section{Helix-breaking mutations prevent maturation of GLT-1}

At least part of this leucine-based domain has been modeled as an $\alpha$-helix (Grunewald and Kanner, 2000; Seal et al., 2000; Slotboom et al., 2001), which could form the basis for a hydrophobic dimerization motif. In leucine zippers, the heptad repeat occurs every two turns of the helix, with individual positions in each heptad designated by the letters "a" through "g" (Hu et al., 1990). Leucine residues are usually found in the "d" position, and in combination with another critical residue in the a position, form an interface composed of primarily hydrophobic residues between parallel $\alpha$-helical coiled domains. Proline residues cannot be tolerated at positions that form the dimer interface, and their introduction in the a positions breaks the helix and subsequent coiled-coil interaction (Hu et al., 1990). To test whether the leucine motif in GLT-1 might depend on a coiled-coil interaction, proline mutations were introduced at three a positions (3P). As was observed with the $6 \mathrm{~L} / 6 \mathrm{~A}$ variant, none of the $3 \mathrm{P}$ mutant transporter migrated as a mature protein, and none of the protein was expressed on the cell surface (Fig. 5). Thus, these data suggest that a coiled-coil interaction may be required for forward trafficking of appropriately assembled transporter complexes from the ER to the Golgi.

Elimination of the ER retention signal rescues cysteine uptake It has been noted previously that arginines in the C-terminal domain of the glutamate transporters, GLAST and EAAC1, are required for transport of glutamate (Conradt and Stoffel, 1995; Bendahan et al., 2000). These arginines in EAAC1 and GLAST occupy positions that are homologous to the second arginine in the GLT-1 RXR motif. Previous studies revealed that this family of proteins transport nondicarboxylic amino acid substrates in addition to dicarboxylic acid substrates such as L-glutamate and L-aspartate. For example, EAAT2 (GLT-1) and EAAT3 (EAAC1) avidly transport L-cysteine (Zerangue and Kavanaugh, 1996; Chen and Swanson, 2003). Mutation of arginine 447 in EAAC1 completely abolishes $\mathrm{Na}^{+}$-dependent glutamate transport without affecting $\mathrm{Na}^{+}{ }_{-}$ dependent cysteine transport. This cysteine transport is insensitive to inhibition by excess glutamate, suggesting that Arg447 is required for interaction with the $\gamma$-carboxy group of glutamate (Bendahan et al., 2000). On the basis of these data, we hypothesized that mutation of arginines in the RMR motif of GLT-1 might also abolish glutamate transport, leaving cysteine uptake intact. To test this possibility, glutamate and cysteine uptake were measured in C6 glioma cells transfected with wildtype and mutant variants of GLT-1 (2R/ $2 \mathrm{~A}, 6 \mathrm{~L} / 6 \mathrm{~A}, 6 \mathrm{~L} / 6 \mathrm{~A}-2 \mathrm{R} / 2 \mathrm{~A})$. Using $\mathrm{L}-\left[{ }^{3} \mathrm{H}\right]-$ glutamate as a substrate, none of these mutant variants of GLT-1 increased the levels of $\mathrm{Na}^{+}$-dependent transport over that observed in control cells (Fig. 6A). Similarly, the $6 \mathrm{~L} / 6 \mathrm{~A}$ variant of GLT-1 did not increase $\mathrm{Na}^{+}$-dependent $\mathrm{L}-\left[{ }^{35} \mathrm{~S}\right]$ cysteine transport above that observed in control cells (Fig. 6B); however, the mutant variant of GLT-1 that lacks both the leucine motif and the ER retention signal $(6 \mathrm{~L} / 6 \mathrm{~A}-2 \mathrm{R} / 2 \mathrm{~A})$ transported $\mathrm{L}-\left[{ }^{35} \mathrm{~S}\right]$-cysteine. These data demonstrate that elimination of the arginine motif in $6 \mathrm{~L} / 6 \mathrm{~A}$ not only restores cell surface expression but also restores functional activity of the transporter. Furthermore, these data indicate that the putative signal required for ER retention overlaps with a site that is important for substrate specificity.

\section{Dominant-negative effects of $6 \mathrm{~L} / 6 \mathrm{~A}$ mutant variant}

Limited data based on chemical cross-linking experiments and freeze-fraction electron microscopy suggest that glutamate transporters self-associate to form homo-oligomers in situ (Haugeto et al., 1996; Eskandari et al., 2000). If multimerization is required before export from the ER, coexpression of the $6 \mathrm{~L} / 6 \mathrm{~A}$ mutant with wild-type GLT-1 might interfere with normal GLT-1 protein processing. To test this possibility, wild-type GLT-1 was cotransfected with increasing amounts of $6 \mathrm{~L} / 6 \mathrm{~A}$. When excess $6 \mathrm{~L} / 6 \mathrm{~A}$ was coexpressed with wild-type GLT-1, both total and cell surface expression were decreased in a dose-dependent manner (Fig. $7 A, B$ ), suggesting that mutant and wild-type GLT-1 can coassemble into complexes. To test for formation of complexes, wild-type GLT-1 and the $6 \mathrm{~L} / 6 \mathrm{~A}$ mutant variant were differentially tagged with HA and FLAG epitopes. These tagged transporters were coexpressed in C6 glioma. An anti-FLAG antibody was used for immunoprecipitation, and the precipitates were 
A
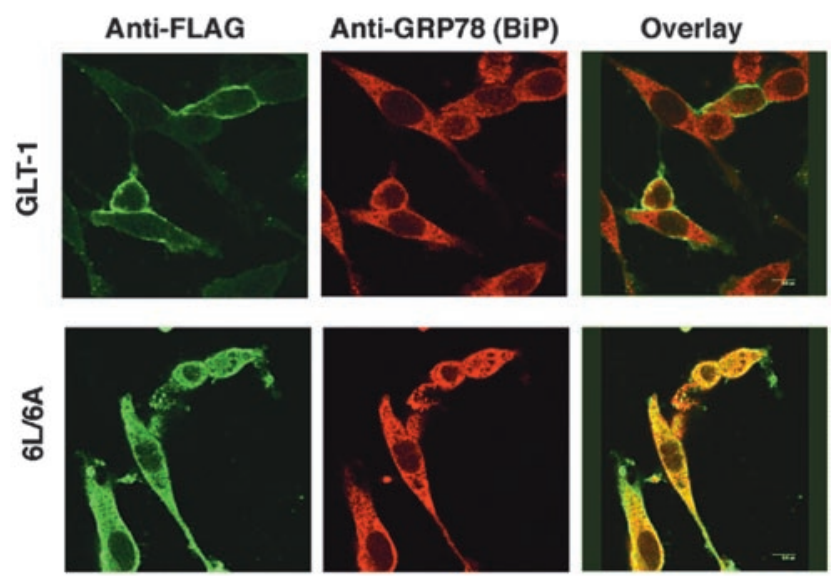

B

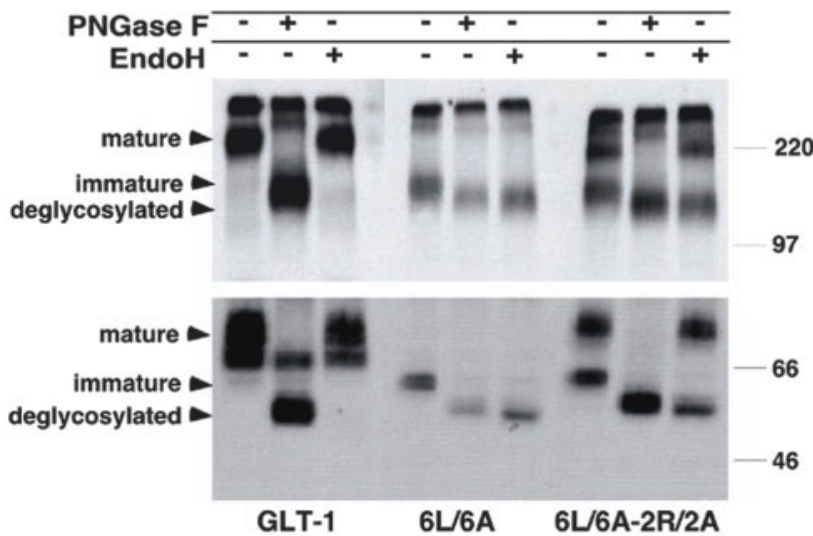

Figure 4. Expression and deglycosylation of wild-type and 6L/6A mutant variants of GLT-1 indicate that the $6 \mathrm{~L} / 6 \mathrm{~A}$ mutant variant does not escape the ER and is not terminally glycosylated. $A$, FLAG epitopes were introduced at the $N$ terminus of the wild-type and mutant $6 \mathrm{~L} / 6 \mathrm{~A}$ variants of GLT-1 to analyze subcellular distribution of these transporters. C6 glioma cells transfected with FLAG-GLT-1 were immunostained for FLAG-tagged transporter (green) and for GRP78 (red). Images are optical cross sections taken near the middle of the cell. FLAG-tagged GLT-1 is expressed at or near the plasma membrane and does not appreciably overlap with staining for the ER chaperon protein, GRP78 (BiP). In contrast, expression of the 6L/6A mutant variant of GLT-1 overlaps with GRP78, indicating that this protein is retained in the ER. This experiment has been reproduced with similar results. $B$, Deglycosylation profiles of wild-type and mutant variants of GLT-1. Expressed proteins were digested with Endo $H$ or PNGase $F$. Mature bands represent a complex glycosylation state, indicating that the protein has passed through the Golgi apparatus and is Endo $\mathrm{H}$ resistant. Immature bands represent the highmannose-type form characteristic of proteins resident in the ER. The top panel shows a lighter exposure of the higher molecular weight "multimer" bands, and the bottom panel shows a darker exposure of lower molecular weight "monomer" bands from the same Western blot. GLT-1 is digested by PNGase F but not Endo $\mathrm{H}$ (the minor PNGase F-resistant band may represent an 0 -linked oligosaccharide). The $6 \mathrm{~L} / 6 \mathrm{~A}$ variant is sensitive to both EndoH and PNGase F. The smaller of the bands observed for $6 \mathrm{~L} / 6 \mathrm{~A}-2 \mathrm{R} / 2 \mathrm{~A}$ is sensitive to both glycosidases, and the larger band is only sensitive to PNGase $F$. These data are representative of three independent experiments.

probed with an anti-HA antibody. Using this approach, we were able to isolate complexes of FLAG-tagged GLT-1 with HA-tagged GLT-1 that migrated predominantly as multimers (Fig. 7C). Similarly, FLAG-tagged 6L/6A coexisted in complexes with HAtagged $6 \mathrm{~L} / 6 \mathrm{~A}$, and as expected, the multimers migrated as lower molecular weight bands. FLAG-tagged GLT-1 also coexisted in complexes with the HA-tagged $6 \mathrm{~L} / 6 \mathrm{~A}$ mutant variant, but both

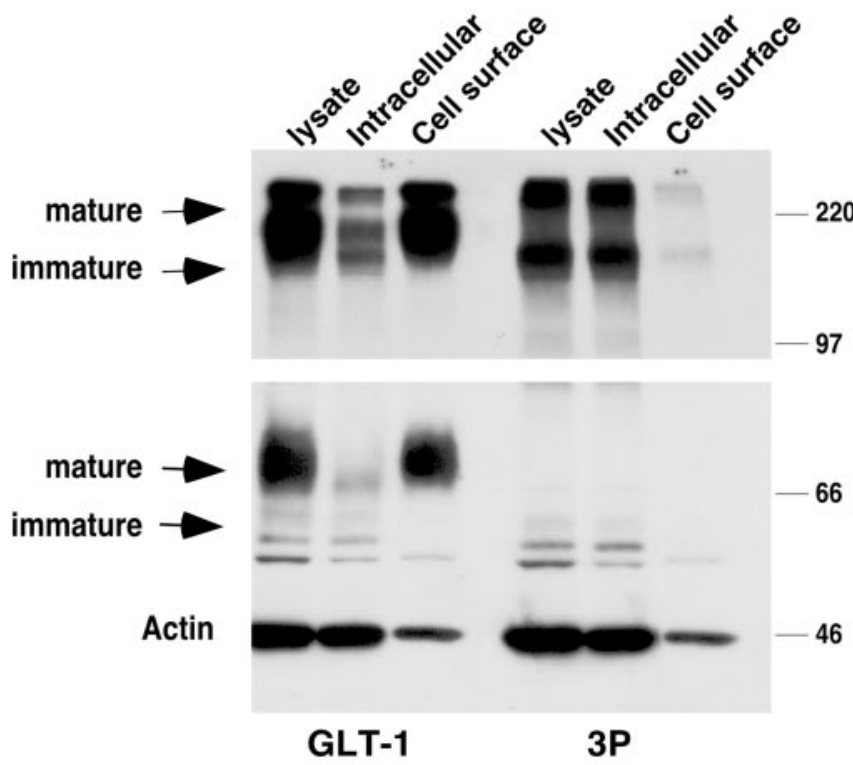

Figure 5. Introduction of helix-breaking proline mutations into the leucine-rich domain in GLT-1 mimicked the expression pattern of the $6 \mathrm{~L} / 6 \mathrm{~A}$ mutant variant of GLT-1, with no mature protein and no protein on the cell surface after expression in C6 glioma. The top and bottom panels are lighter and darker exposures of the same immunoblot to show the effect of mutation on multimer and monomer bands, respectively.
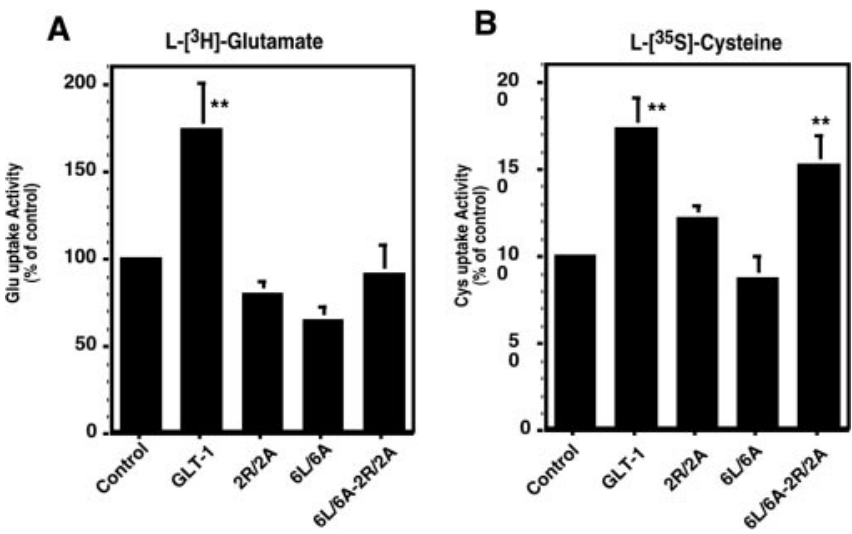

Figure 6. Mutation of the two arginine residues downstream of the $6 \mathrm{~L} / 6 \mathrm{~A}$ motif restores $\mathrm{L}-\left(\left[{ }^{35} \mathrm{~S}\right]\right)$-cysteine transport. $\mathrm{Na}^{+}$-dependent transport of $\mathrm{L}$-glutamate $(A)$ and $\mathrm{L}$-cysteine $(B)$ was measured in $\mathrm{C} 6$ glioma cells transfected with different mutant variants of GLT-1. For glutamate uptake, the mean number of disintegrations per minute observed in the presence of $\mathrm{Na}^{+}$was $7905 \pm 870$ and in the absence of $\mathrm{Na}^{+}$was $1026 \pm 234$. For cysteine, the mean number of disintegrations per minute was $2717 \pm 1360$ in the presence of $\mathrm{Na}^{+}$and $964 \pm 175$ in the absence of $\mathrm{Na}^{+}$. After normalization to the amount of protein in each set of wells, uptake was expressed as a percentage of that observed in mock-transfected control cells. Data are the mean \pm SEM of three (glutamate) or four (cysteine) independent observations and were compared by ANOVA. ${ }^{* *} p<0.01$ compared with control.

mature and immature protein were found in complexes. The fact that both mature and immature bands were observed provides evidence that at certain stoichiometries, complexes of mutant $6 \mathrm{~L} / 6 \mathrm{~A}$ with wild-type GLT-1 can exit the ER. In these same experiments, we probed the immunoprecipitates for EAAC1 that is endogenously expressed in C6 glioma (Davis et al., 1998). In these parallel studies, no EAAC1 immunoreactivity was observed (data not shown), and we found that EAAC1 can be detected in immunoprecipitates using anti-EAAC1-directed antibodies (González et al., 2003), suggesting that it could have been detected had aggregates with GLT-1 been formed after solubilization. 

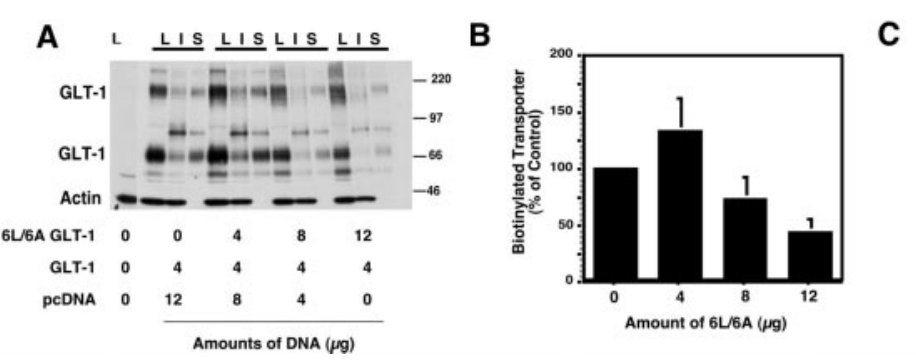

Figure 7. The $6 \mathrm{~L} / 6 \mathrm{~A}$ mutant variant functions as a dominant-negative inhibitor and forms an immunoprecipitable complex with wild-type GLT-1. A, C6 glioma were transiently transfected with wild-type GLT-1 in either the absence or presence of the 6L/6A mutant variant of GLT-1. The total amount of DNA was held constant by varying the amount of empty plasmid (pCDNA3.1). The expression of GLT-1 in the lysate (L), the nonbiotinylated-intracellular fraction (I), and biotinylated - cell surface expression (S) of GLT-1 was examined. Actin immunoreactivity was also examined in these same three fractions. B, Summary of quantitation of four independent experiments. $6 \mathrm{~L} / 6 \mathrm{~A}$ dose-dependently decreased total (data not shown) and cell surface expression of GLT-1 immunoreactivity. Data are the mean \pm SEM. C, GLT-1 and 6L/6A were differentially tagged with HA and FLAG epitopes in the N termini. Different combinations of these epitope-tagged proteins were coexpressed in C6 glioma cells. FLAG-tagged GLT-1 coimmunoprecipiates with HA-tagged GLT-1 or with HA-tagged 6L/6A. FLAG-tagged 6L/6A also interacts with HA-tagged 6L/6A. Data are representative of three independent experiments.
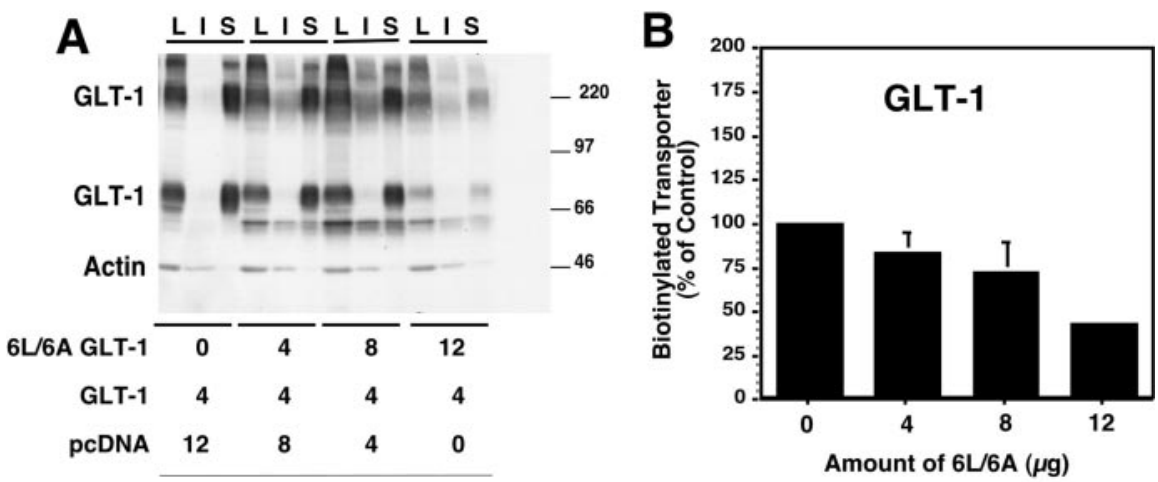

Amounts of DNA $(\mu \mathrm{g})$
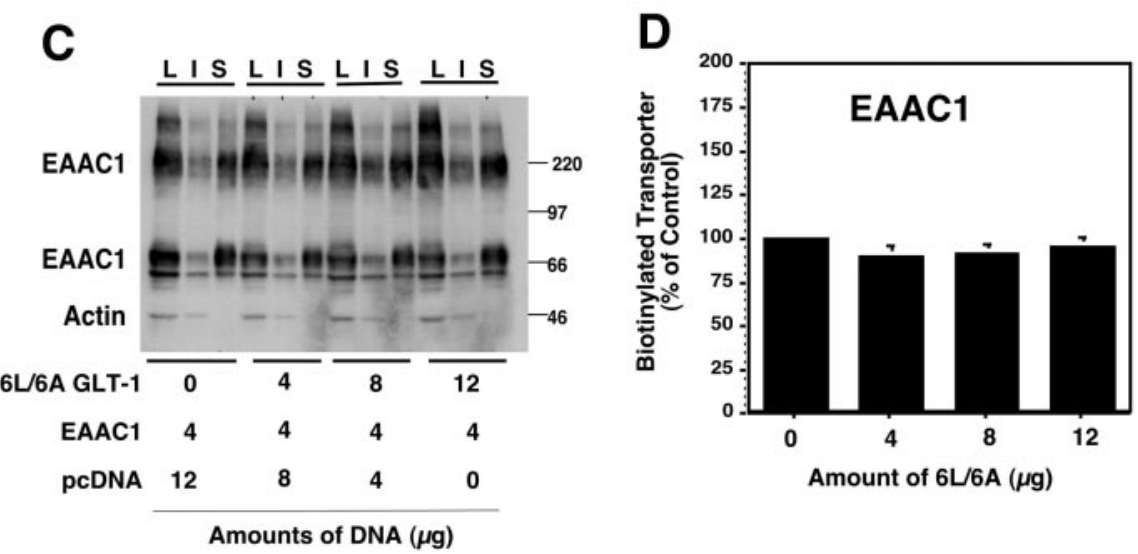

Figure 8. The dominant-negative effect of the $6 \mathrm{~L} / 6 \mathrm{~A}$ variant was specific for GLT-1. HEK293T cells were transiently transfected with wild-type $\mathrm{GLT}-1(A, B)$ or EAAC1 $(C, D)$ in the absence or presence of the $6 \mathrm{~L} / 6 \mathrm{~A}$ variant of GLT-1. The total amount of DNA was held constant by varying the amount of empty plasmid (pCDNA3.1). The expression of GLT-1 or EAAC1 in the lysate (L), the nonbiotinylated-intracellular fraction (I), and biotinylated - cell surface expression (S) of GLT-1 was examined. Actin immunoreactivity was also examined in these same three fractions. $6 \mathrm{~L} / 6 \mathrm{~A}$ dose-dependently decreased total and cell surface expression of GLT-1 but had no effect on expression of EAAC1. Data are the mean \pm SEM of four independent observations.

To determine whether the dominant-negative effect of $6 \mathrm{~L} / 6 \mathrm{~A}$ is specific for the GLT-1 subtype of glutamate transporter, wildtype GLT-1 or EAAC1 was cotransfected with increasing amounts of $6 \mathrm{~L} / 6 \mathrm{~A}$ in HEK293T cells. As was observed in C6 glioma, coexpression of $6 \mathrm{~L} / 6 \mathrm{~A}$ dose-dependently inhibited total and cell surface expression of GLT-1 (Fig. 8A,B); however, coex-

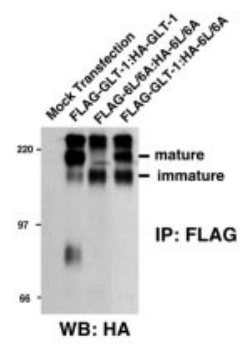

pression with $6 \mathrm{~L} / 6 \mathrm{~A}$ had no effect on either total or cell surface expression of EAAC1 (Fig. 8C,D). Because expression of these proteins is controlled by the same promoter, these later results rule out the possibility that the decrease in GLT-1 expression is related to competition for promoter activators. The fact that no increases in intracellular accumulation of GLT-1 immunoreactivity was observed in these coexpression studies suggests that complexes of mutant and wild-type transporters are being targeted for degradation by the surveillance mechanisms that direct inappropriately trafficked proteins for proteosomal degradation (for review, see Ellgaard et al., 1999; Ellgaard and Helenius, 2003). This possible fate of transporter complexes was not examined in the present study. In the HEK cells, we tested for interactions and the specificity of the immunoprecipitation reaction. These cells were transfected with either FLAG-GLT-1 and HA-GLT-1 or HA-GLT-1 and GLAST. We observed HA-GLT-1 and FLAG-GLT-1 in complexes and found no evidence for GLT-1 and GLAST in complexes (data not shown). Together with the data described in the previous paragraph, these data would suggest that these complexes are not an artifact of postsolubilization aggregation.

The leucine- and arginine-based motifs are sufficient to control Tac trafficking Although these data provide strong evidence that the leucine-based motif may be important for suppression-masking of an arginine-based ER retention signal, we wanted to determine whether these signals function similarly after introduction into another transmembrane protein. A domain that includes both the leucine and arginine motifs was spliced into the $\alpha$ subunit of the interleukin 2 receptor (also called the Tac antigen) to create a TacGLT1-Tac chimera. The $\mathrm{N}$ terminus of Tac is extracellular and contains a single transmembrane domain that starts at amino acids 238 or 239 (Bonifacino et al., 1990; Cosson et al., 1991). Topological models of the glutamate transporters have placed the leucine motif that was identified as being important for masking the putative ER retention signal in an extracellular domain (Fig. 1 $A$ ); therefore, this domain (amino acids 446-477 from GLT-1) was substituted for a comparable domain in Tac (amino acids 238-249). The wild-type variant of these chimeras (called Tac-GLT-1) migrated as a band of $\sim 60 \mathrm{kDa}$ (Fig. $9 A$ ), consistent with the expected molecular weight of mature Tac. As was observed with the $6 \mathrm{~L} / 6 \mathrm{~A}$ variant of GLT-1, the $6 \mathrm{~L} / 6 \mathrm{~A}$ variant of the Tac-GLT-1 chimeras (Tac-6L/6A) migrated as smaller band of $\sim 40 \mathrm{kDa}$. Finally, as was observed with the trans- 
porter constructs, further mutation of the diarginine motif in the Tac-6L/6A chimera (Tac-6L/6A-2R/2A) partially reversed the effects of mutation of the six leucine residues in these chimeras with two clear bands, one at $60 \mathrm{kDa}$ and the other at $40 \mathrm{kDa}$.

The mature form of Tac contains both $\mathrm{N}$-linked and $\mathrm{O}$-linked oligosaccharides (Steen et al., 1998). To confirm that the bands in these experiments represent mature (terminally glycosylated) and immature (partially glycosylated) forms of Tac, the samples were treated with PNGase F or Endo H (Fig. 9B). The higher molecular weight bands observed after expression of either the Tac-GLT-1 or the Tac-6L/6A$2 \mathrm{R} / 2 \mathrm{~A}$ constructs were insensitive to Endo $\mathrm{H}$ and were partially deglycosylated by PNGase $\mathrm{F}$ to a molecular weight of $\sim 50$ $\mathrm{kDa}$, consistent with the mature form that contains $O$-linked oligosaccharides (Standley et al., 2000). In contrast, the 6L/6A variant (Tac-6L/6A) was sensitive to both Endo $\mathrm{H}$ and PNGase F, indicating that this protein is not terminally glycosylated and represents an immature form of this protein. Together, these data demonstrate that the diarginine and the leucine-rich motifs have similar effects on maturation when they are introduced into another protein. This provides further evidence that motifs identified in our study contribute to forward trafficking from the ER to the Golgi and suggest that these motifs function as part of a quality control mechanism during the posttranslational processing that occurs in the ER.

\section{Discussion}

\section{An extracellular leucine motif suppresses ER retention of GLT-1}

Secondary quality control mechanisms during posttranslational processing depend on the presentation or masking of specific sequences within the complex being assembled. Evolving models suggest that these motifs interact with chaperone proteins that either retain inappropriately assembled macromolecules in the ER or facilitate retrieval from the Golgi (Ellgaard and Helenius, 2003). Although most proteins are presumed to have specific surveillance mechanisms that prevent premature export from the ER, surprisingly few of these signals have been identified. The best characterized signal (KDEL) functions to retain chaperones in the ER and is present in the $\mathrm{C}$ terminus of these soluble ER resident proteins. Dibasic residues near either the $\mathrm{C}$ or $\mathrm{N}$ termini (KKXX or KXKXXX) of specific membrane proteins appear to interact with coatamer protein I to facilitate retrieval from the Golgi (Ellgaard and Helenius, 2003). Arginine-based motifs (RXR) have recently been identified in the $\mathrm{C}$ termini of some channels-receptors, including the $\mathrm{K}_{\mathrm{ATP}}$ channels, $\mathrm{GABA}_{\mathrm{B}}$ receptors, and NMDA receptors (Zerangue et al., 1999; MargetaMitrovic et al., 2000; Standley et al., 2000), suggesting that common chaperones may facilitate retention and forward trafficking of these proteins. This motif is found on cytoplasmic domains and therefore resides in the cytoplasm when the protein is being assembled in the ER. Recently, PL(Y/F)(F/Y)XXN was identified as a transmembrane ER retention signal in acetylcholine receptors (Wang et al., 2002). Except for KDEL, which retains ER chaperone proteins, other lumenal retention motifs have not been identified.

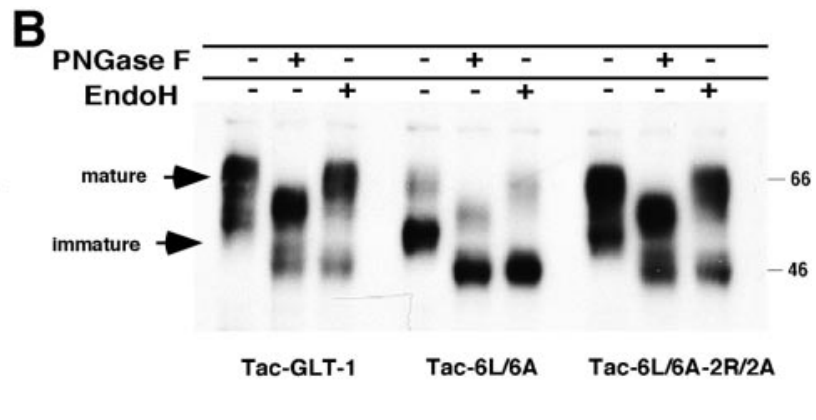

the present study, we identified a motif composed of six leucine residues that is required for export of GLT-1 from the ER. Mutation of these six leucine residues to alanine results in expression of a smaller molecular weight protein that colocalizes in the ER with the chaperone protein, GRP78 (BiP). Unlike wild-type GLT-1, this mutant protein is sensitive to Endo H deglycosylation, is not accessible to a membrane-impermeant biotinylation reagent, and does not transport glutamate, providing several lines of evidence that this motif is required for forward trafficking of GLT-1. Combining mutation of a distal diarginine motif with mutation of these leucine residues partially restored maturation, cell surface expression, and functional activity. Finally, these motifs were sufficient to cause ER retention-release of an unrelated transmembrane protein, Tac. The observed effects of mutation of the leucine-based motif are not likely to be related to simple misfolding, because it is highly improbable that further mutation of two arginine residues would restore appropriate folding and functional activity. The fact that we observe an incomplete rescue with both of these constructs suggests that other mechanisms also contribute to ER retention-quality control or that the double mutants traffic more slowly through the secretory pathway than wild-type transporters. Together, these data provide evidence that the leucine-based motif is important for suppression of an ER retention signal that is mediated by the distal diarginine motif. Interestingly, two studies have identified novel proteins that interact with this general region of the glutamate transporters (Ruggeiro et al., 2003; Watanabe et al., 2003), and one of these proteins, GTRAP3-18 (glutamate transporter-associated protein 3-18) affects transporter maturation, consistent with a chaperonelike protein.

Different groups have examined the transmembrane topology of the glutamate transporters using approaches including cysteine scanning accessibility (Grunewald and Kanner, 2000; Seal et al., 2000; Slotboom et al., 2001). From these studies, the identified leucine motif is located in an extracellular domain (Fig. 1A). From studies with GLAST, the diarginine motif is partly extracellular (Seal et al., 2000), and with studies of GLT-1, the diarginine motif would be embedded in the membrane (Grunewald and Kanner, 2000). Importantly, none of these studies place any part of this domain on the cytoplasmic side of the membrane. Therefore, unlike many of the other previously identified putative ER 
retention signals, the motifs identified in the present study do not face the cytoplasm during assembly of the protein complex.

The glutamate transporters share a high degree of sequence similarity, and not surprisingly, the homology is highest in transmembrane domains (Amara et al., 1998). The motifs identified in the present study are remarkably well conserved within the family of glutamate transporters (Fig. 1C). The diarginine motif is present in all five glutamate transporters and is evolutionarily conserved from insect to human homologs. With the exception of leucine residues 451 and 472, all of the other elements of the leucine-based motif are identical or contain conservative substitutions. If the same residues contribute to forward trafficking of all of the glutamate transporters, this might suggest that the four remaining leucine residues provide the critical minimal determinants required for suppression of the putative retention signal. Although not tested in the present study, it is tempting to speculate that similar mechanisms govern the assembly of the different members of this transporter family.

For most of our studies, we used C6 glioma, a CNS-derived cell line that endogenously expresses the EAAC1 subtype of transporter (Davis et al., 1998) and therefore expresses the appropriate machinery for posttranslational transporter processing. We also used both HEK and COS7 cells, and both of these cells also endogenously express functional transporters (Davis et al., 1998; Tan et al., 1999). Because similar effects on processing were observed with the GLT-1 variants expressed in C6 glioma and with GLT-1-Tac chimeras in COS7 cells, this would suggest that the role of these motifs is not restricted to particular cell types.

\section{Glutamate transporters exit the ER as homo-oligomers}

Chemical cross-linking (Haugeto et al., 1996) and freeze-fracture electron microscopy (Eskandari et al., 2000) studies suggest that glutamate transporters exist as homomultimers and that different transporters do not coassemble as hetero-oligomers. The proposed number of subunits in the complex range from two or three (on the basis of chemical cross-linking) up to five (on the basis of freeze-fracture studies). The fact that differentially tagged GLT- 1 subunits can be coimmunoprecipitated using an antibody that specifically recognizes only one of the epitopes provides evidence for a physical interaction in situ. When equimolar amounts of wild-type GLT-1 and 6L/6A are coexpressed in C6 glioma, there is a modest increase in total and cell surface expression of transporter compared with the levels observed with GLT-1 alone. At higher concentrations, the $6 \mathrm{~L} / 6 \mathrm{~A}$ variant causes a dose-dependent inhibition of wild-type transporter expression. Coimmunoprecipitation of epitope-tagged wild-type GLT-1 with differentially epitope-tagged $6 \mathrm{~L} / 6 \mathrm{~A}$ reveals both immature and mature variants of the complex. Together, these studies suggest that the presence of a single mutant variant in a complex with wild-type GLT-1 is not sufficient to prevent ER export. Therefore, the only way to reconcile these observations is to propose that a minimum of three subunits coassemble into functional transporters.

On the basis of the present study, it is not known whether individual transporter subunits interact through the extracellular leucine motif or whether another protein, possibly a chaperone, interacts with this motif to mask the diarginine motif. Regardless, the fact that the $6 \mathrm{~L} / 6 \mathrm{~A}$ had a dominant-negative effect on and interacts with wild-type GLT-1 provides strong evidence that this domain is not required for interaction between monomers that are coassembled as functional transporters. Together with the fact that $6 \mathrm{~L} / 6 \mathrm{~A}$ did not have a dominant-negative effect on $\mathrm{EAAC} 1$, these data strongly suggest that the residues required for subtype-specific homo-oligomerization lie outside of this domain. Other recent studies have identified leucine repeats that are critical for multimer assembly of the GABA transporter (Schloze et al., 2002), the dopamine transporter (Torres et al., 2003), and the serotonin transporter (Just et al., 2004). All of these leucine motifs lie within transmembrane domains (Sitte and Freissmuth, 2003).

\section{Inappropriate targeting of glutamate transporters}

Altered expression of glutamate transporters has been observed in several neurodegenerative diseases, including Alzheimer's disease, amyotrophic lateral sclerosis (ALS), trauma, and ischemia (Sims and Robinson, 1999; Danbolt, 2001). In some cases, altered expression includes inappropriate targeting of the transporter to specific cellular compartments. For example, in glioma, one of the subtypes (GLAST/EAAT1) is targeted to the nucleus rather than the plasma membrane (Ye et al., 1999). In ALS, there is a large decrease in the levels of GLT-1 protein (Rothstein et al., 1995; Fray et al., 1998) but not mRNA in the spinal cords (Bristol and Rothstein, 1996). Originally, this loss of GLT-1 protein was attributed to selective aberrant splicing of GLT-1 mRNA in affected brain regions (Lin et al., 1998). Others have been unable to detect increased expression of these transcripts in patients with ALS but have observed a surprisingly high level of these transporter transcripts (up to $40 \%$ of the total) in normal tissue (Flowers et al., 2001). These transcripts lack either part or all of the domain identified in the present study. Although it is not clear whether these are disease-specific transcripts or are generally expressed, we have identified determinants that are sufficient to explain how these aberrant proteins could prevent ER export of functional transporter. Because GLT-1 can have toxic consequences (Guo et al., 2002), it is possible that translation of these aberrant transcripts in normal tissue prevents overexpression of GLT-1 by targeting these proteins for degradation before export from the ER.

\section{References}

Amara SG, Sonders MS, Zahniser NR, Povlock SL, Daniels GM (1998) Neurotransmitter transporters: new insights into structure, function and pharmacology. Adv Pharmacol 42:164-168.

Bendahan A, Armon A, Madani N, Kavanaugh M, Kanner B (2000) Arginine 447 plays a pivotal role in substrate interactions in a neuronal glutamate transporter. J Biol Chem 275:37436-37442.

Bonifacino JS, Cosson P, Klausner RD (1990) Colocalized transmembrane determinants for ER degradation and subunit assembly explain the intracellular fate of TCR chains. Cell 63:503-513.

Bristol LA, Rothstein JD (1996) Glutamate transporter gene expression in amyotrophic lateral sclerosis motor cortex. Ann Neurol 39:676-679.

Chen Y, Swanson RA (2003) The glutamate transporters EAAT2 and EAAT3 mediate cysteine uptake in cortical neuron cultures. J Neurochem 84:1332-1339.

Conradt M, Stoffel W (1995) Functional analysis of the high affinity, $\mathrm{Na}(+)$-dependent glutamate transporter GLAST- 1 by site-directed mutagenesis. J Biol Chem 270:25207-25212.

Cosson P, Lankford SP, Bonifacino JS, Klausner RD (1991) Membrane protein association by potential intramembrane charge pairs. Nature 351:414-416.

Danbolt NC (2001) Glutamate uptake. Prog Neurobiol 65:1-105.

Davis KE, Straff DJ, Weinstein EA, Bannerman PG, Correale DM, Rothstein JD, Robinson MB (1998) Multiple signaling pathways regulate cell surface expression and activity of the excitatory amino acid carrier 1 subtype of Glu transporter in C6 glioma. J Neurosci 18:2475-2485.

Ellgaard L, Helenius A (2003) Quality control in the endoplasmic reticulum. Nat Rev Mol Cell Biol 4:181-191.

Ellgaard L, Molinari M, Helenius A (1999) Setting the standards: quality control in the secretory pathway. Science 286:1882-1888.

Eskandari S, Kreman M, Kavanaugh MP, Wright EM, Zampighi GA (2000) 
Pentameric assembly of a neuronal glutamate transporter. Proc Natl Acad Sci USA 97:8641-8646.

Flowers JM, Powell JF, Leigh PN, Andersen P, Shaw CE (2001) Intron 7 retention and exon 9 skipping EAAT2 mRNA variants are not associated with amyotrophic lateral sclerosis. Ann Neurol 49:643-649.

Fray AE, Ince PG, Banner SJ, Milton ID, Usher PA, Cookson MR, Shaw PJ (1998) The expression of the glial glutamate transporter protein EAAT2 in motor neuron disease: an immunohistochemical study. Eur J Neurosci 10:2481-2489.

González MI, Robinson MB (2004) Protein kinase C-dependent remodeling of glutamate transporter function. Mol Int 4:48-58.

González MI, Bannerman PG, Robinson MB (2003) Phorbol myristate acetate-dependent interaction of protein kinase $\mathrm{C} \alpha$ and the neuronal glutamate transporter EAAC1. J Neurosci 23:5589-5593.

Grunewald M, Kanner BI (2000) The accessibility of a novel reentrant loop of the glutamate transporter GLT-1 is restricted by its substrate. J Biol Chem 275:9684-9689.

Grunewald M, Bendahan A, Kanner B (1998) Biotinylation of single cysteine mutants of the glutamate transporter GLT-1 from rat brain reveals its unusual topology. Neuron 21:623-632.

Guo H, Lai L, Butchbach MER, Lin C-LG (2002) Human glioma cells and undifferentiated primary astrocytes that express aberrant EAAT2 mRNA inhibit normal EAAT2 protein expression and prevent cell death. Mol Cell Neurosci 21:546-560.

Haugeto $\varnothing$, Ullensveng K, Levy LM, Chaudhry FA, Honore T, Neilsen M, Lehre KP, Danbolt NC (1996) Brain glutamate transporter proteins form homomultimers. J Biol Chem 271:27715-27722.

Hu JC, O'Shea EK, Kim PS, Sauer RT (1990) Sequence requirements for coiled-coils: analysis with $\lambda$ repressor-GCN4 leucine zipper fusions. Science 250:1400-1403.

Huh KH, Wenthold RJ (1999) Turnover analysis of glutamate receptors identifies a rapidly degraded pool of the $N$-methyl-D-aspartate receptor subunit, NR1, in cultured cerebellar granule cells. J Biol Chem 274:151-157.

Hurtley SM, Helenius A (1989) Protein oligomerization in the endoplasmic reticulum. Ann Rev Cell Biol 5:277-307.

Just H, Sitte HH, Schmid JA, Freissmuth M, Kudlacek O (2004) Identification of an additional interaction domain in transmembrane domains 11 and 12 that supports oligomer formation in the human serotonin transporter. J Biol Chem 279:6650-6657.

Kalandadze A, Wu Y, Robinson MB (2002) Protein kinase C activation decreases cell surface expression of the GLT-1 subtype of glutamate transporter. Requirement of a carboxyl-terminal domain and partial dependence on serine 486. J Biol Chem 277:45741-457450.

Klausner RD, Sitia R (1990) Protein degradation in the endoplasmic reticulum. Cell 62:611-614.

Lin C-LG, Bristol LA, Jin L, Dykes-Hoberg M, Crawford T, Clawson L, Rothstein JD (1998) Aberrant RNA processing in a neurodegenerative disease: the cause for absent EAAT2, a glutamate transporter, in amyotrophic lateral sclerosis. Neuron 20:589-602.

Margeta-Mitrovic M, Jan YN, Jan LY (2000) A trafficking checkpoint controls $\mathrm{GABA}_{\mathrm{B}}$ receptor heterodimerization. Neuron 27:97-106.

Mennerick S, Shen W, Xu W, Benz A, Tanaka K, Shimamoto K, Isenberg KE, Krause JE (1999) Substrate turnover by transporters curtails synaptic glutamate transients. J Neurosci 19:9242-9251.

Robinson MB (1999) The family of sodium-dependent glutamate transporters: a focus on the GLT-1/EAAT2 subtype. Neurochem Int 33:479-491.

Rothstein JD, Van Kammen M, Levey AI, Martin LJ, Kuncl RW (1995) Se- lective loss of glial glutamate transporter GLT-1 in amyotrophic lateral sclerosis. Ann Neurol 38:73-84.

Rothstein JD, Dykes-Hoberg M, Pardo CA, Bristol LA, Jin L, Kuncl RW, Kanai Y, Hediger M, Wang Y, Schielke JP, Welty DF (1996) Knockout of glutamate transporters reveals a major role for astroglial transport in excitotoxicity and clearance of glutamate. Neuron 16:675-686.

Ruggeiro AM, Vidensky S, Rothstein JD (2003) GTRAP3-18 protein is able to regulate the activity of excitatory amino acid transporters through alterations in Asn-linked glycosyl processing. Soc Neurosci Abstr 29:372.315.

Schloze P, Freissmuth M, Sitte HH (2002) Mutations within an intramembrane leucine heptad repeat disrupt oligomer formation of the rat GABA transporter 1. J Biol Chem 277:43682-43690.

Seal RP, Leighton BH, Amara SG (2000) A model for the topology of excitatory amino acid transporters determined by the extracellular accessibility of substituted cysteines. Neuron 25:695-706.

Sims KD, Robinson MB (1999) Expression patterns and regulation of glutamate transporters in the developing and adult nervous system. Crit Rev Neurobiol 13:169-197.

Sitte HH, Freissmuth M (2003) Oligomer formation by $\mathrm{Na}^{+}-\mathrm{Cl}-$ coupled neurotransmitter transporters. Eur J Pharmacol 479:229-236.

Slotboom DJ, Konnings WN, Lolkema JS (2001) Cysteine-scanning mutagenesis reveals a highly amphipathic, pore-lining membrane-spanning helix in the glutamate transporter GltT. J Biol Chem 276:14282-14287.

Standley S, Roche KW, McCallum J, Sans N, Wenthold RJ (2000) PDZ domain suppression of an ER retention signal in NMDA receptor NR1 splice variants. Neuron 28:887-898.

Steen PV, Rudd PM, Dwek RA, Opdenakker G (1998) Concepts and principles of O-linked glycosylation. Crit Rev Biochem Mol Biol 33:151-208.

Tan J, Zelenaia O, Rothstein JD, Robinson MB (1999) Expression of the GLT-1 subtype of $\mathrm{Na}^{+}$-dependent glutamate transporter: pharmacological characterization and lack of regulation by protein kinase C. J Pharmacol Exp Ther 289:1600-1610.

Tanaka K, Watase K, Manabe T, Yamada K, Watanabe M, Takahashi K, Iwama H, Nishikawa T, Ichihara N, Kikuchi T, Okuyama S, Kawashima N, Hori S, Takimoto M, Wada K (1997) Epilepsy and exacerbation of brain injury in mice lacking the glutamate transporter GLT-1. Science 276:1699-1702.

Teasdale RD, Jackson MR (1996) Signal-mediated sorting of membrane proteins between the endoplasmic reticulum and the Golgi apparatus. Annu Rev Cell Dev Biol 1996:27-54.

Tong G, Jahr CE (1994) Block of glutamate transporters potentiates postsynaptic excitation. Neuron 13:1195-1203.

Torres GE, Carneiro A, Seamans K, Fiorentini C, Sweeney A, Yao W-D, Caron MG (2003) Oligimerization and trafficking of the human dopamine transporter. J Biol Chem 278:2731-2739.

Wang J-M, Zhang L, Yao Y, Viroonchatapan N, Rothe E, Wang Z-Z (2002) A transmembrane motif governs the surface trafficking of nicotinic acetylcholine receptors. Nat Neurosci 5:963-970.

Watanabe M, Robinson MB, Kalandadze A, Rothstein JD (2003) GPS1, interacting protein with GLT-1. Soc Neurosci Abstr 29:372.316.

Ye Z, Rothstein JD, Sontheimer H (1999) Compromised glutamate transport in human glioma cells: reduction-mislocalization of sodiumdependent glutamate transporters and enhanced activity of cystineglutamate exchange. J Neurosci 19:10767-10777.

Zerangue N, Kavanaugh MP (1996) Interaction of L-cysteine with a human excitatory amino acid transporter. J Physiol (Lond) 493:419-423.

Zerangue N, Schwappach B, Jan YN, Jan LY (1999) A new ER trafficking signal regulates the subunit stoichiometry of plasma membrane $\mathrm{K}_{\mathrm{ATP}}$ channels. Neuron 22:537-548. 